\title{
MILHO PIPOCA CONSORCIADO COM FEIJÃO EM DIFERENTES ARRANJOS DE PLANTAS ${ }^{1}$
}

\author{
Antonio Luiz Viegas Neto², Rafael Heinz², Manoel Carlos Gonçalves², \\ Allan Michel Pereira Correia ${ }^{2}$, Leandro Henrique de Souza Mota $^{2}$, Willian Dias Araújo ${ }^{2}$
}

\begin{abstract}
POPCORN INTERCROPPED WITH BEAN

UNDER DIFFERENT PLANT ARRANGEMENTS

The intercropping of popcorn and bean is an alternative for small farmers, by providing higher profits and a better use of the crop area, besides reducing loss risks. This study aimed to evaluate different popcorn and bean intercropping systems. The experiment was carried out in an experimental field owned by the Universidade Federal da Grande Dourados, in Dourados, Mato Grosso do Sul State, Brazil. The experimental design was randomized blocks, with four replications, with treatments arranged in a split-plot scheme, with plots consisting of two popcorn cultivars (Zélia and BRS Ângela) and subplots consisting of three intercropping systems with popcorn and the BRS MG Pioneiro bean (popcorn + bean in the popcorn row, popcorn + bean between the popcorn rows, and corn + bean in the popcorn row + bean between the popcorn rows), and popcorn under monocropping system. The intercropping systems evaluated did not affect the popcorn yield, and bean sown in the popcorn row + between the popcorn rows resulted in a higher yield. In general, the intercropping between the two species decreased bean yield, however, due to the equivalent area index values, it was $50 \%$ to $91 \%$ more efficient than the monocropping systems.
\end{abstract}

KEY-WORDS: Zea mays everta B.; Phaseolus vulgaris L.; equivalent area index.

\section{INTRODUÇÃO}

A consorciação de culturas, sistema comumente adotado por pequenos produtores, representa uma estratégia com potencial para aumento de produção por unidade de área cultivada (Bezerra Neto et al. 2001). Os pequenos produtores buscam, com o sistema, redução dos riscos de perdas, maior aproveitamento da sua propriedade e maior retorno econômico (Portes \& Silva 1996).

\section{RESUMO}

O cultivo de milho pipoca em consórcio com feijão é uma alternativa para o pequeno produtor, por proporcionar maior retorno econômico e aproveitamento da área de cultivo, além de diminuir os riscos de perda. Neste trabalho, avaliaramse diferentes sistemas de consórcio de milho pipoca com feijão. $\mathrm{O}$ experimento foi realizado em campo experimental da Universidade Federal da Grande Dourados, em Dourados (MS). Utilizou-se delineamento experimental de blocos ao acaso, com quatro repetições, e tratamentos em esquema de parcelas subdivididas, no qual as parcelas constituíram-se de duas cultivares de milho pipoca (Zélia e BRS Ângela) e as subparcelas de três sistemas de consórcio de milho pipoca com feijão BRS MG Pioneiro (milho + feijão na linha do milho, milho + feijão na entrelinha do milho e milho + feijão na linha do milho + feijão na entrelinha do milho) e milho pipoca em monocultivo. Os sistemas de consórcio avaliados não afetaram a produtividade do milho pipoca e a semeadura do feijão na linha + entrelinha do milho resultou em maior produtividade da leguminosa. De maneira geral, o consórcio das duas espécies reduziu os rendimentos do feijoeiro, entretanto, devido aos valores do Índice de Equivalência de Área, foi 50\% a 91\% mais eficiente que os monocultivos.

PALAVRAS-CHAVE: Zea mays everta B.; Phaseolus vulgaris L.; índice de equivalência de área.

Entende-se por consórcio de culturas o sistema de cultivo em que a semeadura de duas ou mais espécies é realizada em uma mesma área, de modo que uma das culturas se desenvolva com a outra, em todo ou em, pelo menos, parte do seu ciclo (Portes \& Silva 1996).

Devido à sua importância, o cultivo do feijão em consórcio com outras culturas é procedimento comum no Brasil. Segundo Costa \& Marinho (2000), a cultura do feijoeiro apresenta altos riscos de produção, devido ao ataque de pragas e doenças, sendo esta

1. Trabalho recebido em mar./2011 e aceito para publicação em fev./2012 ( ${ }^{\circ}$ registro: PAT 13720).

2. Universidade Federal da Grande Dourados, Faculdade de Ciências Agrárias, Dourados, MS, Brasil.

E-mails: antonio-viegas@hotmail.com,rafael_heinz@hotmail.com, manoelgoncalves@ufgd.edu.br, allan_michel@hotmail.com, leandromota22@bol.com.br,williandiasaraujo@hotmail.com. 
a principal desvantagem do monocultivo, em relação ao consórcio, o qual propicia melhor uso da terra, melhor controle de erosão, diversificação da dieta alimentar, maior renda bruta e maior estabilidade de produção. No consórcio do milho comum e feijão, vários trabalhos foram realizados, disponibilizando, desta maneira, estratégias para a melhoria da sua eficiência (Flesch 2002, Denega et al. 2004, Maciel et al. 2004a e 2004b).

Em sistema de consórcio, são observados rendimentos de feijão menores do que no monocultivo. Andrade et al. (2001), avaliando o cultivo de milho pipoca e do feijoeiro em diferentes sistemas de consórcio, em dois espaçamentos do milho pipoca $(0,80 \mathrm{~m}$ e $1,0 \mathrm{~m})$, obtiveram redução da produtividade do feijoeiro de $70 \%$ e $50 \%$, respectivamente. A redução da produtividade do feijão, quando consorciado com o milho, ficou em torno de $71,2 \%$, em trabalho realizado por Costa \& Silva (2008), e foi superior a $60 \%$, em experimento conduzido por Maciel et al. (2004a).

Existem, na literatura, poucas informações a respeito do consórcio do feijoeiro com o milho pipoca, produto que, por sua demanda e valor comercial, representa boa alternativa para pequenos produtores. As variedades de milho pipoca, quando comparadas aos milhos comuns, apresentam plantas mais baixas, com colmos mais finos e folhas mais estreitas, mais prolíficas, menos produtivas e mais susceptíveis a pragas e doenças (Gama et al. 1990).

No consórcio, as espécies cultivadas normalmente diferem em altura e em distribuição das folhas no espaço, dentre outras características morfológicas que podem levar as plantas a competir por energia luminosa, água e nutrientes. Por esta razão, a escolha do melhor arranjo das plantas e da época ideal de semeadura é crucial no desempenho da consorciação (Flesch 2002).

Os arranjos dos sistemas de consórcio utilizados são bastante variáveis, em função da região e das cultivares escolhidas. Costa \& Marinho (2000) concluíram que, para o Acre, o ideal seria o plantio de três fileiras de feijão ou de feijão-caupi para uma fileira de milho. Contudo, em trabalho realizado por Flesch (2002), os arranjos mais eficientes para a cultura do milho foram os plantios de uma fileira de milho alternada com uma fileira de feijão e duas fileiras de milho alternadas com duas fileiras de feijão.

Assim, objetivou-se, neste trabalho, avaliar a viabilidade agronômica e a eficiência do uso da terra, no consórcio de cultivares de milho pipoca e feijão, em diferentes arranjos de plantas.

\section{MATERIAL E MÉTODOS}

O estudo foi realizado em 2009, no campo experimental da Faculdade de Ciências Agrárias da Universidade Federal da Grande Dourados (UFGD), em Dourados (MS) (22 $11^{\prime} 55^{\prime}$ 'S, 54 $56^{\circ} 07^{\prime \prime} \mathrm{W}$ e $452 \mathrm{~m}$ de altitude). O clima da região é classificado como Cwa (Köppen), ou seja, mesotérmico úmido, apresentando precipitação média acumulada de $1.427 \mathrm{~mm}$ (Fietz \& Fisch 2006).

O experimento foi implantado em Latossolo Vermelho distroférrico, apresentando as seguintes características granulométricas e químicas da camada 0-20 cm de profundidade: 76,2 dag $\mathrm{kg}^{-1}$ de argila; 16,6 dag kg $^{-1}$ de silte; 7,2 dag kg-1 de areia; 33,6 $\mathrm{g} \mathrm{dm}^{-3}$ de matéria orgânica; 5,5 de $\mathrm{pH}\left(\mathrm{H}_{2} \mathrm{O}\right)$; $18 \mathrm{mg} \mathrm{dm}^{-3}$ de fósforo; $0,64 \mathrm{cmol}_{\mathrm{c}} \mathrm{dm}^{-3}$ de potássio; $0,06 \mathrm{cmol}_{\mathrm{c}} \mathrm{dm}^{-3}$ de alumínio; $4,4 \mathrm{cmol}_{\mathrm{c}} \mathrm{dm}^{-3}$ de cálcio; $1,8 \mathrm{cmol}_{\mathrm{c}} \mathrm{dm}^{-3}$ de magnésio; $2,42 \mathrm{cmol}_{\mathrm{c}} \mathrm{dm}^{-3} \mathrm{de} \mathrm{H}+\mathrm{Al}$; $6,84 \mathrm{cmol}_{\mathrm{c}} \mathrm{dm}^{-3}$ de soma de bases; $9,26 \mathrm{cmol}_{\mathrm{c}} \mathrm{dm}^{-3}$ de T; e 73,9\% de V.

$\mathrm{O}$ delineamento experimental utilizado foi o de blocos ao acaso, com quatro repetições, e os tratamentos dispostos no esquema de parcelas subdivididas. As parcelas constituíram-se de duas cultivares de milho pipoca: Zélia (híbrido triplo da Empresa Pioneer) e BRS Ângela (cultivar da Embrapa). Nas subparcelas, estudaram-se três sistemas de consórcio, nos seguintes arranjos espaciais: milho + feijão na linha do milho; milho + feijão na entrelinha do milho; milho + feijão na linha do milho + feijão na entrelinha do milho; e milho pipoca em monocultivo. Utilizou-se o feijão BRS MG Pioneiro, cultivar Carioca, desenvolvido pela Embrapa.

A área total da subparcela foi de $18,0 \mathrm{~m}^{2}$, com quatro linhas espaçadas em $0,9 \mathrm{~m}$ de milho pipoca, com 5,0 $\mathrm{m}$ de comprimento. Quando o feijão foi avaliado na entrelinha e na linha do milho, o espaçamento, para o feijão, foi de $0,90 \mathrm{~m} \mathrm{e}$, no arranjo com feijão na linha + entrelinha, o espaçamento foi de $0,45 \mathrm{~m}$. A área útil da subparcela, para o feijão na entrelinha, foi de $13,5 \mathrm{~m}^{2}$.

O preparo da área experimental foi realizado no sistema convencional, com uma aração e duas gradagens, e a semeadura efetuada na safrinha, em $25 / 04 / 2009$, utilizando-se $420 \mathrm{~kg} \mathrm{ha}^{-1}$ do formulado 04-14-8, contendo zinco. O feijão, na entrelinha, 
recebeu a mesma adubação do milho e, na linha, não recebeu adubação adicional. Na semeadura, foram utilizadas sementes suficientes para, após o desbaste, aos 20 dias após a emergência, a obtenção de cinco plântulas de milho e dez plântulas de feijão por metro linear. Na cobertura nitrogenada, aos 30 dias após a emergência, foram aplicados $60 \mathrm{~kg} \mathrm{ha}^{-1}$ de $\mathrm{N}$, tanto no milho quanto no feijão na entrelinha, utilizando-se o mesmo procedimento da adubação inicial, ou seja, o feijão na linha não recebeu adubação adicional.

Na época de pré-colheita, em cada subparcela, em cinco plantas ao acaso da área útil de cada subparcela, efetuaram-se as seguintes avaliações no milho pipoca: Altura de planta - correspondeu à média das medições feitas do nível do solo à inserção da folha-bandeira; Altura de inserção da $1^{\text {a }}$ espiga - média das distâncias do nível do solo até a inserção da espiga superior; Número de espigas por planta - valor médio da contagem do número de espigas viáveis; Diâmetro do colmo - medindo-se o segundo nó a partir da base do nível do solo; Comprimento da espiga debulhada - medindo-se todo o tamanho da espiga; Diâmetro da espiga debulhada - medindo-se a região do terço médio da espiga. Segundo Catapatti et al. (2008), para a avaliação de caracteres de pré-colheita, em milho pipoca, podem ser adotadas amostras de 5 a 25 plantas por parcela, sem afetar a precisão experimental.

Após a colheita, efetuaram-se as seguintes avaliações: Produtividade - determinada em função da massa de grãos debulhados colhidos das plantas das duas linhas centrais da subparcela; e Capacidade de expansão - determinada pela razão entre o volume de pipoca expandida e o volume de grãos antes do pipocamento. Para avaliar a capacidade de expansão, utilizaram-se três amostras de $30 \mathrm{~mL}$ de grãos de cada subparcela, medidas em proveta graduada de $50 \mathrm{~mL}$, estouradas em pipoqueira comum, e o volume de pipoca expandido foi medido em proveta graduada de $1.000 \mathrm{~mL}$.

No feijoeiro, efetuaram-se as seguintes avaliações: Número de grãos por vagem - média da contagem do número de grãos de dez vagens por planta; Massa de 100 grãos - pesados a partir dos grãos debulhados, em gramas; e Produtividade massa de grãos debulhados colhidos das plantas das duas linhas inteiras centrais da subparcela, em kg ha-1. As avaliações foram realizadas em dez plantas por subparcela.

Determinou-se, ainda, para cada sistema avaliado, o Índice de Equivalência de Área (IEA), que é definido como a área relativa de terra, em cultivo solteiro, necessária para se obter os mesmos rendimentos que o cultivo consorciado. O seu cálculo é feito pela seguinte fórmula: IEA $=\mathrm{MC} / \mathrm{MS}+\mathrm{FC} / \mathrm{FS}$, onde $\mathrm{MC}$ e FC são os rendimentos de grãos do milho pipoca e feijão consorciado e MS e FS são os rendimentos do milho pipoca e feijão, em cultivo solteiro (Vieira 1984 e 1985). Para o cálculo da relação do feijão, empregaram-se os rendimentos médios da cv. BRS MG Pioneiro, em monocultivo, obtidos em conjunto com o experimento de consócio com o milho pipoca, com produtividade de $909,26 \mathrm{~kg} \mathrm{ha}^{-1}$.

Os dados foram submetidos a análise de variância e as médias comparadas pelo teste Tukey, a $5 \%$. Utilizou-se o sistema de análise estatística SAEG (Ribeiro Júnior 2001), para análise dos dados.

\section{RESULTADOS E DISCUSSÃO}

$\mathrm{Na}$ análise de variância, houve efeito significativo dos diferentes sistemas de consócio, para as variáveis altura de planta e diâmetro de colmo, o que significa que o milho consorciado teve estes valores afetados, devido à presença do feijão. As duas cultivares de milho pipoca diferenciaram-se na capacidade de expansão do grão, comprimento e diâmetro de espiga debulhada (Tabela 1).

As duas cultivares de milho pipoca não diferiram, com relação à produtividade, no sistema consorciado e no cultivo solteiro (Tabela 1), provavelmente devido ao fato de o feijão não concorrer com o milho pelos fatores de produção. Maciel et al. (2004b), trabalhando com consórcio de milho e feijão, encontraram diferença de produção apenas entre as cultivares de milho, não verificando diferenças para o feijão.

Flesch (2002) observou que o cultivo antecipado ou simultâneo de milho com feijão proporciona a manutenção da produtividade do milho no consórcio, em relação ao cultivo solteiro. Maciel et al. (2004b) obtiveram os maiores valores para as características agronômicas do milho na população de 50.000 plantas ha-1. Vieira (1999) afirma que, para a obtenção de um alto rendimento de grãos, em um sistema consorciado, a principal cultura deve manter alta densidade populacional.

A cultivar Zélia apresentou maiores valores de capacidade de expansão (CE) dos grãos de milho pipoca e comprimento de espiga, quando comparada à cultivar BRS Ângela, independentemente do 
Tabela 1. Médias das duas cultivares de milho pipoca, nos diferentes sistemas de consórcio, para produtividade (PROD), capacidade de expansão (CE), altura de planta (AP), altura de espiga (AE), tamanho de espiga (TE), diâmetro de colmo (DC), diâmetro de espiga (DE) e número de espigas por planta (NEP) (Dourados, MS, 2009).

\begin{tabular}{|c|c|c|c|c|c|c|c|c|}
\hline \multirow{2}{*}{ Tratamento } & \multirow{2}{*}{$\begin{array}{l}\text { PROD } \\
\mathrm{kg} \mathrm{ha}^{-1}\end{array}$} & \multirow{2}{*}{$\mathrm{CE}$} & $\mathrm{AP}$ & $\mathrm{AE}$ & TE & DC & $\mathrm{DE}$ & \multirow{2}{*}{ NEP } \\
\hline & & & \multicolumn{3}{|c|}{$-\mathrm{cm}$} & \multicolumn{2}{|c|}{$\mathrm{mm}$} & \\
\hline \multicolumn{9}{|l|}{ Cultivar } \\
\hline Zélia & $1.289,20$ & $11,60 \mathrm{a}$ & 154,69 & 86,03 & $18,02 \mathrm{a}$ & 19,85 & $32,47 \mathrm{~b}$ & 1,48 \\
\hline BRS Ângela & $1.031,50$ & $10,94 \mathrm{~b}$ & 148,03 & 80,41 & $15,26 \mathrm{~b}$ & 18,66 & $35,58 \mathrm{a}$ & 1,46 \\
\hline \multicolumn{9}{|l|}{ Sistema de plantio } \\
\hline Linha & $1.016,20$ & 11,92 & $147,18 \mathrm{ab}$ & 79,65 & 16,36 & $17,96 \mathrm{~b}$ & 34,04 & 1,43 \\
\hline Entrelinha & $1.160,20$ & 11,17 & $155,78 \mathrm{ab}$ & 85,45 & 16,47 & $20,32 \mathrm{a}$ & 34,05 & 1,50 \\
\hline Linha + entrelinha & $1.193,50$ & 10,79 & 144,98 b & 82,50 & 16,46 & $17,04 \mathrm{~b}$ & 33,90 & 1,38 \\
\hline Milho solteiro & $1.271,50$ & 11,21 & $157,50 \mathrm{a}$ & 85,28 & 17,29 & $21,70 \mathrm{a}$ & 34,11 & 1,58 \\
\hline Média & $1.160,40$ & 11,27 & 151,36 & 83,22 & 16,64 & 19,25 & 34,02 & 1,47 \\
\hline DMS & 290,31 & 2,60 & 11,46 & 10,33 & 1,43 & 1,89 & 1,63 & 0,29 \\
\hline CV - A (\%) & 24,90 & 6,90 & 6,10 & 8,80 & 3,60 & 6,90 & 3,40 & 13,70 \\
\hline CV - B (\%) & 34,10 & 16,40 & 16,00 & 22,60 & 6,10 & 8,40 & 8,60 & 18,90 \\
\hline
\end{tabular}

Médias seguidas de letras diferentes, nas colunas, diferem estatisticamente pelo teste Tukey, a $5 \%$.

sistema utilizado. Miranda et al. (2003), estudando o potencial de melhoramento de cultivares de milho pipoca, verificou que a cultivar Zélia obteve o maior valor para capacidade de expansão, dentre as nove cultivares avaliadas. A capacidade de expansão ficou entre $10,4 \mathrm{~mL} \mathrm{~mL}^{-1}$ e $11,6 \mathrm{~mL} \mathrm{~mL}^{-1}$, para as duas cultivares, valores baixos para $\mathrm{CE}$, segundo Galvão et al. (2000), considerando-se que uma boa cultivar de milho pipoca deve apresentar CE acima de $21 \mathrm{~mL} \mathrm{~mL}^{-1}$. Para o diâmetro de espiga, a cultivar BRS Ângela apresentou os maiores valores (em média 35,58 mm) (Tabela 1).

O milho pipoca em consórcio com feijão, na linha e na entrelinha, causou redução significativa na altura de plantas e diâmetro de colmo (Tabela 1). Andrade et al. (2001), estudando o consórcio de milho pipoca com feijão, não obtiveram diferença significativa na altura de plantas, contudo, para o diâmetro de colmo, observaram redução, devido à maior competição interespecífica com o feijão.

O consórcio de feijão na linha do milho reduziu apenas o diâmetro de colmo do milho. Em trabalho realizado por Andrade et al. (2001), o diâmetro de colmo, com o feijão na linha do milho, não diferiu do milho solteiro, apresentando valores menores que na entrelinha.

Para os dados de produtividade, número de grãos por vagem e massa de 100 grãos, houve efeito significativo apenas para produtividade, nos sistemas de consórcio (Tabela 2). Costa \& Silva (2008), trabalhando com sistemas de consórcio de milho e feijão, não encontraram diferenças no número de grãos por vagem e massa de 100 grãos, concluindo que os diferentes sistemas de cultivo não alteram o processo fisiológico de formação das sementes, mantendo as características morfológicas e de massa do grão da cultivar, sendo outros os fatores responsáveis pela redução da produtividade.

Maciel et al. (2004a) justificam o fato de o número de grãos por vagem e a massa de 100 grãos sofrerem pouca interferência do consórcio devido a estas características serem intrínsecas à cultivar, sofrendo menos interferência do ambiente.

A variedade de feijão BRS MG Pioneiro produziu mais em consórcio $\left(761,06 \mathrm{~kg} \mathrm{ha}^{-1}\right)$ com a cultivar

Tabela 2. Valores médios dos componentes de produção de feijão, nos diferentes sistemas de consórcio, com duas cultivares de milho pipoca (Dourados, MS, 2009).

\begin{tabular}{lccc}
\hline \multirow{2}{*}{ Tratamento } & \multirow{2}{*}{$\begin{array}{c}\text { Número de } \\
\text { grãos vagem }\end{array}$} & \begin{tabular}{c} 
Massa de \\
\cline { 3 - 4 }
\end{tabular} & \multicolumn{2}{c}{$\mathrm{g}$} & $\mathrm{kg} \mathrm{ha}^{-1}$ \\
\hline Cultivar & & & \\
Zélia & & 17,82 & $666,92 \mathrm{~b}$ \\
BRS Ângela & 6,35 & 18,55 & $761,06 \mathrm{a}$ \\
\hline Sistema & 6,67 & & \\
Linha & & 18,62 & $637,50 \mathrm{~b}$ \\
Entrelinha & 6,54 & 18,02 & $618,98 \mathrm{~b}$ \\
Linha + entrelinha & 6,51 & 17,91 & $885,49 \mathrm{a}$ \\
\hline Média & 6,48 & 18,18 & 713,99 \\
\hline DMS & 6,50 & 2,54 & 260,30 \\
\hline CV - A (\%) & 0,72 & 5,60 & 22,80 \\
CV - B (\%) & 4,30 & 10,50 & 29,20 \\
\hline
\end{tabular}

Médias seguidas de letras diferentes, nas colunas, diferem estatisticamente pelo teste Tukey, a $5 \%$. 
BRS Ângela do que com a cultivar Zélia. A semeadura simultânea do feijão na linha + entrelinha do milho pipoca, por se tratar de sistema de consórcio com relação de 2 linhas de feijão para 1 linha de milho, tendo maior número de plantas $\mathrm{ha}^{-1}$, resultou em maior produtividade (Tabela 2). As semeaduras de feijão na linha e na entrelinha do milho apresentaram resultados equivalentes, apesar de a semeadura na linha não ser adubada. Resultados semelhantes também foram observados em consórcio da leguminosa com o milho comum, por Andrade et al. (1974) e Ramalho (1988).

Observando-se os valores da relação $\mathrm{C} / \mathrm{M}$ (Tabela 3), pode-se constatar que a redução da produtividade do milho pipoca foi de, no máximo, $20 \%$. O feijão, quando cultivado apenas na linha, obteve maior desenvolvimento do que quando cultivado na linha e na entrelinha, competindo mais com o milho e causando maior redução de produtividade da gramínea. Quando cultivado na entrelinha, a redução da produtividade do feijão chegou a um máximo de $32 \%$. O feijão apresentou menor crescimento quando cultivado apenas na entrelinha, pois, quando cultivado na linha do milho, cresceu mais sobre a planta do milho, tendo maior incidência de luz e desenvolvimento.

$\mathrm{O}$ milho, por ser uma espécie $\mathrm{C}_{4}$, apresenta menor competição por água e gás carbônico do que o feijão, que é uma espécie $\mathrm{C}_{3}$, não caracterizando-se por perdas significativas, quando submetido ao consórcio com o feijão, contrariamente ao que ocorre com o feijão. As plantas $\mathrm{C}_{4}$ são adaptadas às condições ambientais onde a irradiância e a temperatura são elevadas, sendo ainda mais tolerantes ao estresse hídrico (Kerbauy 2004).

Os valores do IEA evidenciaram que o consórcio das duas espécies foi, aproximadamente, $50 \%$ a 91\% mais eficiente que o monocultivo de cada cultura separadamente. Bezerra et al. (2007) obtiveram índice de equivalência de área, para o consórcio de sorgo com feijão-caupi, de 1,32, com as culturas arranjadas em fileira alternadas, na mesma proporção.

Tabela 3. Relações C/M (rendimento de grãos no consórcio/ rendimento em monocultivo) e índice de equivalência de área (IEA) dos sistemas de consócio de milho pipoca + feijão (Dourados, MS, 2009).

\begin{tabular}{lccc}
\hline \multicolumn{1}{c}{ Sistema } & C/M milho & C/M feijão & IEA \\
\hline Linha & 0,80 & 0,70 & 1,50 \\
Entrelinha & 0,91 & 0,68 & 1,59 \\
Linha + entrelinha & 0,94 & 0,97 & 1,91 \\
\hline
\end{tabular}

Pesquisa de Morgado \& Willey (2003), avaliando o efeito de populações de plantas de feijão em consórcio com o milho e níveis de nitrogênio, comprovou a eficiência do consórcio, por meio dos valores do índice de equivalência de área da produção de espiga, vagem e biomassa, que foram superiores aos respectivos monocultivos.

Santos (2007), trabalhando com o consórcio de milho verde e feijão, durante dois anos agrícolas, obteve índice de equivalência de área de 1,19 a 1,83, dependendo da combinação das cultivares de milho e feijão.

\section{CONCLUSÕES}

1. As duas cultivares de milho pipoca podem ser consorciadas com o feijão sem perda de produtividade, independentemente do arranjo espacial do feijão.

2. A maior produtividade do feijão foi obtida com a semeadura simultânea do feijão na linha e na entrelinha do milho pipoca.

3. De maneira geral, o consórcio das duas espécies reduziu os rendimentos do feijoeiro, mas mostrou-se, pelos valores do IEA, $50 \%$ a $91 \%$ mais eficiente que os monocultivos.

\section{REFERÊNCIAS}

ANDRADE, M. A. et al. Consorciação de feijoeiro (Phaseolus vulgaris L.) com cultivares de milho (Zea mays L.) de porte diferente. Revista Agros, Lavras, v. 4, n. 2, p. 23-30, 1974.

ANDRADE, M. J. B. et al. Avaliação de sistemas de consórcio de feijão com milho-pipoca. Ciência e Agrotecnologia, Lavras, v. 25, n. 2, p. 242-250, 2001.

BEZERRA, A. P. A. et al. Rendimento, componentes da produção e uso eficiente da terra nos consórcios sorgo $\mathrm{x}$ feijão-de-corda e sorgo x milho. Ciência Agronômica, Fortaleza, v. 38, n. 1, p. 104-108, 2007.

BEZERRA NETO, F. et al. Desempenho da cenoura em cultivo solteiro e consorciado com quatro cultivares de alface em dois sistemas de cultivo em faixas. Horticultura Brasileira, Brasília, DF, v. 19, n. 2, supl., 2001. 1 CD-ROM.

CATAPATTI, T. R. et al. Tamanho de amostra e número de repetições para avaliação de caracteres agronômicos em milho-pipoca. Ciência e Agrotecnologia, Lavras, v. 32, n. 3, p. 855-862, 2008.

COSTA, A. S. V. da; SILVA, M. B. da. Sistemas de consórcio milho-feijão para a região do Vale do Rio Doce, Minas Gerais. Ciência e Agrotecnologia, Lavras, v. 32, n. 2, p. 663-667, 2008. 
COSTA, J. G.; MARINHO, J. T. S. Efeito de diferentes arranjos no consórcio milho-feijão e milho-caupi no Acre, Brasil. Acta Amazonica, Manaus, v. 30, n. 3, p. 363-368, 2000.

DENEGA, S.; JADOSKI, S. O.; MALLMANN, N. Avaliação da produtividade no consórcio de milho e feijão. Guairacá, Guarapuava, v. 20, n. 1, p. 17-31, 2004.

FIETZ, C. R.; FISCH, G. F. O clima da região de Dourados, MS. Dourados: Embrapa Agropecuária Oeste, 2006.

FLESCH, R. D. Efeitos temporais e espaciais no consórcio intercalar de milho e feijão. Pesquisa Agropecuária Brasileira, Brasília, DF, v. 37, n. 1, p. 51-56, 2002.

GALVÃO, J. C. C.; SAWAZAKI, E.; MIRANDA, G. V. Comportamento de híbridos de milho-pipoca em Coimbra, Minas Gerais. Ceres, Viçosa, v. 47, n. 270, p. 201-218, 2000.

GAMA, E. E. G. et al. Milho pipoca. Informe Agropecuário, Belo Horizonte, v. 14, n. 165, p. 12-16, 1990.

KERBAUY, G. B. Fisiologia vegetal. Rio de Janeiro: Guanabara Koogan, 2004.

MACIEL, A. D. et al. Comportamento do feijoeiro em cultivo consorciado com milho em sistema de plantio direto. Acta Scientiarum Agronomy, Maringá, v. 26, n. 3, p. 273-278, 2004a.

MACIEL, A. D. et al. Comportamento do milho consorciado com feijão em sistema de plantio direto. Acta Scientiarum Agronomy, Maringá, v. 26, n. 3, p. 309-314, 2004b.
MIRANDA, G. V. et al. Potencial de melhoramento e divergência genética de cultivares de milho-pipoca. Pesquisa Agropecuária Brasileira, Brasília, DF, v. 38, n. 6, p. 681-688, 2003.

MORGADO, L. B.; WILLEY, R. W. Effects of plant population and nitrogen fertilizer on yield and efficiency of mayze-bean intercropping. Pesquisa Agropecuária Brasileira, Brasília, DF, v. 38, n. 11, p. 1257-1264, 2003.

PORTES, T. A.; SILVA, C. C. Cultivo consorciado. In: ARAÚJO, R. S. et al. (Eds.). Cultura do feijoeiro comum no Brasil. Piracicaba: Potafos, 1996. p. 619-638.

RAMALHO, M. A. P. Consórcio nas regiões Sudeste e Centro-Oeste. In: ZIMMERMANN, M. J. O.; ROCHA, M.; YAMADA, T. (Eds.). Cultura do feijoeiro. Piracicaba: Potafos, 1988. p. 415-437.

RIBEIRO JÚNIOR, J. I. Análises estatísticas no SAEG. Viçosa: UFV, 2001.

SANTOS, N. C. B. Comportamento de cultivares de feijoeiro e de milho verde em cultivo solteiro e consorciado. 2007. 98 f. Tese (Doutorado em Sistemas de Produção)Faculdade de Engenharia de Ilha Solteira, Universidade Estadual Paulista, Ilha Solteira, 2007.

VIEIRA, C. Estudo monográfico do consórcio milho-feijão no Brasil. Viçosa: UFV, 1999.

VIEIRA, C. Índice de equivalência de área. Informe Agropecuário, Belo Horizonte, v. 10, n. 118, p. 12-13, 1984.

VIEIRA, C. O feijão em cultivos consorciados. Viçosa: UFV, 1985. 